\title{
EVALUATION OF RISK IMPACT ON IMPLEMENTATION OF INNOVATION PROJECTS WITHIN THE FRAMEWORK OF MACHINE-BUILDING QUASI-INTEGRATION STRUCTURES
}

\author{
Sergii Solntsev ${ }^{1}$, Zhanna Zhygalkevych ${ }^{2}$, Maryna Kravchenko³
}

\begin{abstract}
The risk management of innovation project can improve the level of risk control of quasi-integration structures (QIS), so as to make more effective decisions, reduce investment losses and achieve mutual benefit as well. Therefore, an assessment of the risk impact on implementation of innovation project makes this study relevance. The purpose of this paper is to analyze the impact of market risks on the success of innovative QIS engineering projects with the involvement of an economic-probabilistic model based on a conjoint analysis. Research methodology. The article substances the feasibility and results of the application of the method of conjoint analysis - one of the methods of mathematical psychology - to assess the impact of risks on the effectiveness of innovative projects implemented within quasi-integration structures in the engineering complex. Findings. The most likely scenarios for implementing an innovative project in terms of the impact of risk events on the financial result had been found with a help of a conjoint procedure with a fractional factorial design. The relative impact of each risk on the success of the innovation project was evaluated. The rule of deciding on the eligibility of an innovative project by the participants of machine-building QIS was formulated on the basis of the technique of the internal rate of investment return (IRR). Research limitations. The developed methodology is proposed to be used in assessing the impact of risks on innovative projects within machine-building quasi-integration structures. The proposed method of assessing the impact of risks on the financial results of innovative projects within the machine-building QIS can be used in more general situations. Practical implications. The methodology was tested on the example of an innovation project within an innovation and technology cluster, which included six participants: mechanical engineering companies, a service company, a scientific institution and an educational institution. The market and specific inter-corporate risks that influence the results of innovative projects within machine-building QISs were identified and evaluated for operationalization. According to the results of implementation of the methodology, the feasibility of implementing an innovative project within the innovation-technological cluster was substantiated. Originality/value. The scientific novelty of this study is the use of a conjoint analysis methodology to assess the impact of market risks.
\end{abstract}

Key words: machine-building, Ukraine, quasi-integration structures, innovative project, risks, conjoint analysis.

JEL Classification: C19, D81, G31

\section{Introduction}

Mechanical engineering plays a systematic role in the structure of Ukraine's economy. However, during the period of independence, mechanical engineering significantly lost its position, the share of engineering products in total industrial production decreased fourfold - from $30.5 \%$ in 1990 to $7.6 \%$ in 2019 . There are several reasons for this decline. One of the reasons is the technological obsolescence of production and manufactured products, which is a consequence of ineffective privatization, which resulted in a large-scale breakdown, first of all, of organizational-economic and production-technological ties between machinebuilding enterprises and institutions interacting with them. This led to a decrease in competitiveness of products, a decrease in investmentand innovation activity of enterprises. Another reason is the continuation of the military-political conflict in Donbass. As a result, many

\footnotetext{
Corresponding author:

${ }^{1}$ National Technical University of Ukraine “Igor Sikorsky Kyiv Polytechnic Institute”, Ukraine.

E-mail: s.solntsev@kpi.ua

ORCID: https://orcid.org/0000-0002-8820-3528

${ }^{2}$ National Technical University of Ukraine "Igor Sikorsky Kyiv Polytechnic Institute”, Ukraine.

E-mail: zh.zhygalkevych@kpi.ua

ORCID: https://orcid.org/0000-0002-5847-1302

${ }^{3}$ National Technical University of Ukraine "Igor Sikorsky Kyiv Polytechnic Institute", Ukraine.

E-mail: m.kravchenko@kpi.ua

ORCID: https://orcid.org/0000-0001-5405-0159
} 
machine-building enterprises in Luhansk and Donetsk regions have suspended or stopped production.

According to the experience of the economically developed countries, one of the directions of reconstruction of the Ukrainian machine-building industry and the enterprises that cooperate with it is to create and develop specific hybrid forms of integration quasi-integration structures.

The concept of this study is based on the idea that QIS is a voluntary spatial partnership of cooperative industries and scientific institutions on the basis of integrated usage of available resources, aimed at achieving the highest economic efficiency and strengthening market positions, which feature is the lack of control over the assets ownership.

Machine-building QIS is the union of machinebuilding enterprises and enterprises that are gradually involved in the production and technological process on a contractual basis, leaving the independence of the entities, which are the parts of it.

These structures are different from other integrated structures by mobility, adaptability, flexibility and soft management (Solntsev S. et al., 2019).

The most promising forms of engineering QIS are: business groups acting as strategic alliances; networkingassociations; clusters; virtual organizations.

Therefore, machine-building QISs are self-adjusting, self-learning, self-organizing and self-developmental systems, characterized by sustainability (with respect to environmental changes) and synergy (with respect to internal effects). The main advantages of machinebuilding QISs are the following features:

- creation of new markets;

- technological leadership;

- new markets entry;

- increase in sales;

- reduction of transaction costs;

- activation of innovations.

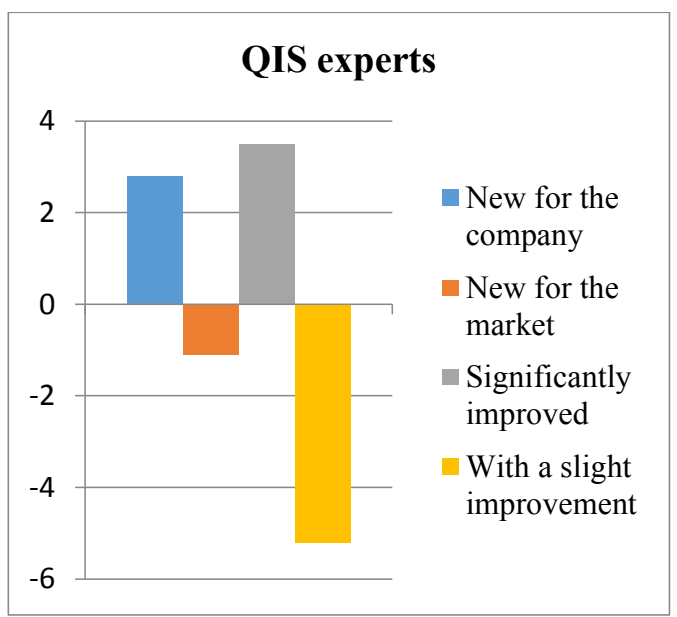

The outlined advantages of creating machine-building QISs substantiate these opportunities by reducing the risks and increasing the synergistic effects of joint innovation projects.

An important factor in deciding whether to participate in the implementation of innovative projects is the attitude of entrepreneurs to the risks - they may be prone to, neutral or reluctant. Motivating factors for entrepreneurs to make a positive decision may be the attractiveness of innovative projects, such as: product novelty, innovative product component, potential financial benefits. The paper (Solntsev S. et. Al., 2020) presents a comparative analysis of innovative projects attractiveness for QISs experts and external experts. The attractiveness of an innovation project for the QIS expert group is more related to the new innovative product for QIS. Whereas for independent experts, projects related to the traditional product for the company and in the already developed markets are preferable (Figure 1).

Adhering to the concepts of perceived and acceptable risk, the above article states that QIS representatives perceive the risks associated with entering the market for innovative products in old and new markets at a lower level than non-integrated companies. As QIS is a selforganizing economic system, this may indicate that one of the incentives for establishing internal sustainable economic ties between participants is their innovative orientation. QIS integration can also be explained by the participants' desire to protect and strengthen their market positions in a strategic perspective.

This difference in risk perception emphasizes the specificity of risk assessment of innovative projects within the QIS and therefore requires special research. So, the basis of empirical data on risk assessment of innovative projects within the QIS are surveys of QISs experts. For these reasons, the authors propose to use the conjoint analysis toolkit. The essence of the method is to jointly consider the product characteristics and

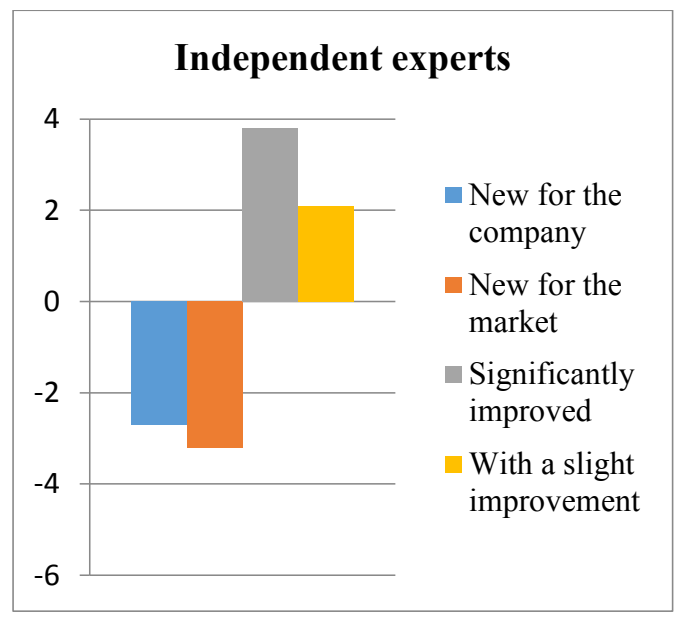

Figure 1. Distribution of perception of innovative projects by degree of novelty

Source: (Solntsev, Zhygalkevych, 2020) 
other environmental factors, which promote or interfere with commodity exchange operations, and thus affect the financial results of the project. This method is often and successfully used in marketing researches for the implementation of models of multi-attribution of goods, namely, when testing the concept of goods, packaging, name, price, advertising, etc. (Cherenkov A., 1999). Researches and their implementation into modern business activities have proven the effectiveness of conjoint data collection and processing procedures (Sawtooth Software, 2017). However, the authors are not aware of examples of studies on the use of conjoint analysis in assessing the impact of risks on innovative projects.

Therefore, this article is focused on an in-depth study of the impact of risks on the performance of innovative projects within the machine-building QIS, using the method of conjoint analysis.

\section{Review of the scientific literature}

Risk analysis is increasingly important in today's economy as the degree of environmental uncertainty increases. The expansion of project activity in industrial enterprises is an issue for project risk management (Behrens, Hawranek, 1991; Kaplan, Mikes, 2016; McConnell, 2016).

The study of literature has allowed to conditionally divide the methods of risk assessment into the following groups.

1. Methods of probability distribution analysis. The traditional approach here is the Value-at-Risk (VaR) (Chen, 2013). These methods are mainly used to assess risks in the financial markets. At the same time, R. Miura (2000) applied this method in assessing market risks.

The group of probability distribution methods is based on the assumption of the type of distribution and requires a large database of empirical data, which makes it impossible to use in evaluating innovative projects.

2. Scenario methods. These methods concentrate on establishing cause and effect relationships for risk events. The main advantage of their application is the orientation to identify the root causes of the risk. One of the methods of this group is the fault tree analysis, according to which the degree of influence of risks on their identification is quantified (Xing Y. et al., 2017). Another type of scenario method is the event tree analysis. In the work of Ferdous (Ferdous R. et al., 2011), this approach to assessing the probable consequences of an adverse event is combined with fuzzy set theory.

3. Methods offuzzy sets. They are based on aggregated indicators that describe the probability of risks. Specificity of project risk assessment with the help of fuzzy set theory is given in the works of T. Bragina and G. Tabunshchyk (2011). In Q. Wang (2009) paper, this approach is used in the assessment of marketing project risks.
In the case of many scenarios, the use of fuzzy sets methods is limited by the complexity of fuzzy inference rules.

4. Methods of simulation (Monte Carlo simulation). In project risk assessment, such methods rely on the computer generation of input variables, with subsequent statistical estimation of quantitative risk indicators (Miorando R.F. et al., 2014). The distribution of input variables is determined either a priori, based on theoretical assumptions (for example, assumptions on variables to be normally distributed, identically distributed, etc.), or a posteriori based on a large array of statistics.

The lack of statistics on innovative products makes it difficult to use the methods of this group.

5. Methods of analyzing the sensitivity of performance indicators. The essence of the methods of this group is to analyze changes in financial and economic indicators, depending on changes in project parameters. Techniques for assessing the risks of promoting innovation based on the sensitivity of net present value (NPV), internal rate of return on investment (IRR), discounted profitability index (DPI), discounted payback period (DPP) are given in the work of Dreshchinsky (Dreshchinsky V. et al., 2010). In the work of Havenaar (2012) the use of performance indicators sensitivity analysis methods was proposed to assess risks in QIS, in particular, in strategic alliances.

As for disadvantages of the sensitivity analysis methods, we can include the fact that the estimation of each parameter occurs at fixed other parameters, which does not take into account their mutual influence.

Themethods ofassessing the effectiveness ofinvestment projects also include the traditional ones: the method of adjusting the discount rate (risk premium) and the method of reliable equivalents (the method of reliability coefficients). A common feature of these methods is cash flow forecasting with project risk adjustment: in the first case - the adjustment of the discount rate, and in the second case - the adjustment of cash flows directly. A detailed description of these methods can be found, for example, in the works of Slepukhina (Slepukhina J. et al., 2007). In the study presented by the authors, the determination of the investment attractiveness of the project is carried out on the basis of combining these methods. It should be noted that the combination of different risk assessment methods is a promising direction for project risk assessment.

Among the qualitative and quantitative methods, the risk assessment of investment projects proposed by Kovalev P. (2017) attracts attention. His research identified the tasks and formalized stages of assessing the risks of investment projects and the risks of integration processes in value chains. The author made a qualitative assessment of investment risks by the method of cognitive modeling and proposed a certain algorithm for its use. 
Turning to innovative projects, we emphasize that the decision to invest them is based on the tradeoff between the desire for strategic leadership in the market (the strategy of "cherry picking", the acquisition of significant market share, etc.) and the perception of risk. Thus, O. Laburtseva (2012) states that minimizing the risk of innovation is tantamount to abandoning innovation. In the work of VargasHernández (2010), it is noted that, on the one hand, companies need innovations to be competitive in the market, but on the other hand, one of the most important aspects of innovation is risk. If companies do not take risks into account, the project fails, and if they apply many risk management systems, these methods can stifle innovation.

Consequently, there is currently no consensus on assessing the impact of enterprise project risks on innovations. However, it can be argued that significant influence is exerted on the market and marketing risks, the relevance of which is revealed in the works of modern Ukrainian scientists: S. Illiashenko (2010), Solntsev S. and Ovchynnikova A. (2011), O. Laburtseva (2012). Interesting, in our view, are the ideas for quantifying market and marketing risks in the works of Thuesen K. (2007), Wang Q. (2009), Rutkauskas A. and Ginevičius I. A. (2011), which can be used in risk assessment of innovative products.

There are also practical methods for managing project risks. In particular, the enterprise risk management (ERM) concept (Committee of Sponsoring Organizations of the Treadway Commission, 2007) is widely used to identify all the risks a company is exposed to (Etges, 2017). Similarly, ISO 31000 focuses on structuring the risk management process (International Organization for Standardization, 2009). An attempt has been made to standardize probabilistic and statistical risk models in business practice (Morgan, 1996). There are enough risk analysis, evaluation and management models available, such as Original Spiral Model, ProRisk, KGRisk and more.

These methods of risk identification, assessment and management are certainly relevant. However, existing methods do not allow us to fully determine the level of risk impact on the performance of innovative projects. Only a small number of methods focus on identifying the real risks of innovation, but most focus solely on the probability of success of projects without taking into account their economic dimension.

Conjoint analysis is related to the methods of mathematical psychology and in its origin a fundamental role was played by the article wrote by psychologist Luce R. Duncan and statistics made by John W. Tukey (1964). Krantz D. et al. (1971) in his article has investigated behavioral aspects in psychometrics using the composite approach, which is the basis of conjoint analysis. GreenPaul E. and Vithala R. Rao (1971) confirmed the effectiveness of successful use of conjoint analysis in marketing research, from which, in principle, innovation begins.

Not dwelling in detail on the review of the literature on conjoint analysis, we note the reviews of the conjoint paradigm founders Green Paul E. and Srinivasan V. (1990), which outline the directions of theoretical and practical research of this method, as well as the work of Hauser J. et al. (2004), Green P.E. et al. (2001), Steiner M., and Meißner M. (2018), which can track the evolution of conjoint procedures. However, the possibilities of using conjoint analysis as a risk study tool remain insufficiently disclosed. In particular, there is no understanding of the probability of potential cash flow deviations that are proposed to be evaluated by the conjoint analysis method that affect the economic and probabilistic expected profitability of innovative projects within the machine-building QIS. Considering the above mentioned in-depth study of conjoint analysis and how it is used in assessing the impact of risks on the performance of innovative projects seems to be a timely and relevant problem.

The aim of this work is to analyze the impact of market risks on the success of innovative machine-building QIS projects with the involvement of an economicprobabilistic model based on a conjoint analysis. The model focuses on identifying project participants' tendency to risk, identifying the most influential risks for innovative projects within machine-building QISs, and identifying the most likely scenarios of risk events affecting cash flow deviations that underlie the economic and probable estimation.

\section{Research tasks}

QIS, as an economic system that operates on the principles of self-organization, has an inherent property of synergy. The risks of inter-corporate relations specific to QISs are taken into consideration in terms of successful implementation of the innovation project. QIS synergies tend to reduce market risks compared to non-integrated companies. Increasingly, this applies to innovative projects that require a large resource base. The established inter-corporate relations in QIS can be broken by dissonance in the perception of the innovative project. This can counteract the synergistic effects that are characteristic of quasi-integration and, as a consequence, increase the risks of successful project implementation.

In order to select the most likely scenarios of the impact of risks on the financial result, the need to solve the first problem arises.

T1: To identify specific market risks which affect the results of innovative projects within the machine-building QIS in order to operationalize them.

The decision to participate in an innovation project is based on an assessment of the risk events that have the 
greatest impact on the effectiveness of the innovation projects. This requires the following task.

T2: To identify the most likely project scenarios in terms of the impact of risk events on the financial result, indicating the relative impact of each risk.

The decision to invest in a project is based on the criteria for choosing between two alternatives to participate or not participate in the innovation project. The solution of this problem is considered possible based on the creation of an analytic model of the objective function that takes into account market risks and the definition of a decision algorithm that will be based on the characteristics of the objective function. Thus, the following task arises.

T3: To formulate a decision rule on the acceptability of an innovative project by the participants of machinebuilding QIS.

\section{Research methodology}

Quantitative estimation is based on formalization of input data to such a level that enables the use of mathematical tools. The absence of statistics on the assessment and forecasting of planned results of innovation (profitability, market share, consumer response to innovative products) indicates the impossibility of using classical methods of forecasting such as multidimensional regression, the theory of time series, models of moving averages, classical autoregressive models etc. This is the basis for using the conjoint analysis methodology (Hanke, Wichern, 2009).

Our work proposes a procedure for collecting, processing and interpreting data to evaluate the impact of risks on the financial performance of innovative projects within machine-building QISs based on the use of the methodology of conjoint analysis, programming language R, NPV and IRR.

(T1) The identification of the risks of innovative projects was based on the method of focus group interviews (Merton, Robert K. et al., 1946). Initially, potential market risks were identified when implementing projects within the framework of QISs, and then the most influential risks were selected by consensus (Hsu C.-C. et al., 2007).

(T2) It is proposed to indicate the relative impact of each risk on a success of an innovation project with the help of a conjoint analysis methodology, which is one of the powerful tools in the process of commercialization of innovative ideas. It allows to carry out market analysis and, as practice shows, to accurately predict market reaction to an innovative product (a series of products within the project). Identifying market threats and opportunities for a project to bring an innovative product to the market helps reduce risks and, therefore, prevent financial and reputational losses.
As respondents 7 QISs experts were involved to assess the importance of attributes and their levels, each expert was as asked to rank the profiles (scenarios) in order of their likelihood, starting with the most probable option in the direction of reducing the probability.

One of the following models is usually used to process the data in the conjoint procedure, in order to evaluate the experts' preferences: 1 ) a vector model; 2) ideal point model; 3) part-worth model (Green Petal., 2001). It is suggested to use a part-worth model to solve the designated and further problems.

The impact of risk events on the project's financial results was assessed on the basis of a scenario approach. Each scenario consisted of all possible combinations of identified R1-R5 risks (described below) and a percentage of the planned cash flow input. The set of all eligible scenarios ranged from the most probable to the less probable, revealed the relative impact of each risk, estimated the level of planned cash flow input.

The impossibility of referencing existing scientific sources of information on risk assessment using conjoint analysis (unfortunately, the authors do not have the relevant information) and the multidimensional nature of interpretation of the study's findings justify the desire for a detailed presentation of the theoretical and statistical model based on the conjoint approach.

Six attributes have been identified to determine the most likely project scenarios in terms of the impact of risk events on the financial result. According to the conjoint procedure, the attributes are selected as follows: the first one is a percentage of the planned cash flow input, and the other five are the risks (R1-R5). There are two levels for attributes (R1) - (R5): "risk event will occur" (hereinafter referred to as "TRUE") and "risk event will not occur" (hereinafter referred to as "FALSE"). Six levels were selected for the attribute "percentage of planned cash flow input": $100 \%, 80 \%$, $60 \%, 40 \%, 20 \%, 0 \%$.

If a fully-crossed factorial design experiment was used, there would be 384 profiles in the experiment, which would make the choice of "cards" unrealistic. Based on computer simulation using the $\mathrm{R}$ programming language, an incomplete experiment plan of acceptable size with a number of profiles of 16 pieces was formed.

The categorical regression equation was compiled by determining the presence of an attribute $j$ in a profile with level i:

$$
x_{i j}=\left\{\begin{array}{c}
1, \text { if } j-\text { level of an } i-\text { attribute is in the card } \\
0, \text { inother case }
\end{array}\right.
$$

These variables are predictors of the categorical regression equation:

$$
y=a_{0}+\sum_{i} \sum_{j} a_{i j} x_{i j}+\varepsilon,
$$

where $a_{0}, a_{i j}$ - regression coefficients, $\varepsilon$ - random fluctuations; and as the dependent variable $y$ the inverse ranks of the cards are selected. 
Table 1

Dummy variables in the empirical equation of categorical regression

\begin{tabular}{|c|c|c|c|c|c|c|c|c|c|c|c|c|c|c|c|c|}
\hline \multirow{3}{*}{$\begin{array}{l}\text { Attributes } \\
\begin{array}{l}\text { Levels of } \\
\text { attributes, } \%\end{array}\end{array}$} & \multirow{2}{*}{\multicolumn{6}{|c|}{$\%$ planned net flow }} & \multicolumn{10}{|c|}{ Risks } \\
\hline & & & & & & & \multicolumn{2}{|c|}{$\mathrm{R}_{1}$} & \multicolumn{2}{|c|}{$\mathrm{R}_{2}$} & \multicolumn{2}{|c|}{$\mathrm{R}_{3}$} & \multicolumn{2}{|c|}{$\mathrm{R}_{4}$} & \multicolumn{2}{|c|}{$\mathrm{R}_{5}$} \\
\hline & 100 & 80 & 60 & 40 & 20 & 0 & 幽 & 号 & 疍 & 嘪 & 紊 & 咜 & 幽 & 㞻 & 幽 & 㓌 \\
\hline Dummy variables & & $\mathrm{x}_{11}$ & $\mathrm{x}_{12}$ & $\mathrm{x}_{13}$ & $\mathrm{x}_{14}$ & $\mathrm{x}_{15}$ & & $\mathrm{x}_{21}$ & & $\mathrm{x}_{31}$ & & $\mathrm{x}_{41}$ & & $\mathrm{x}_{51}$ & & $\mathrm{x}_{61}$ \\
\hline $\begin{array}{l}\text { Regression } \\
\text { coefficients }\end{array}$ & 0 & $\hat{a}_{11}$ & $\hat{a}_{12}$ & $\hat{a}_{13}$ & $\hat{a}_{14}$ & $\hat{a}_{15}$ & 0 & $\hat{a}_{21}$ & 0 & $\hat{a}_{31}$ & 0 & $\hat{a}_{41}$ & 0 & $\hat{a}_{51}$ & 0 & $\hat{a}_{61}$ \\
\hline
\end{tabular}

Source: Own elaboration

The empirical categorical regression equation was calculated using the least squares method:

$$
\hat{y}=\hat{a}_{0}+\sum_{j=1}^{5} \hat{a}_{1 j} x_{1 j}+\sum_{i=2}^{6} \hat{a}_{i 1} x_{i 1}
$$

where $\hat{a}_{0}, \hat{a}_{i j}$ - estimation of regression coefficients, $x_{i j}$ - dummy variables (Malhotra N., Birks D., 2007), defined in Table 1.

The weights in the empirical categorical regression equation that are compiled on the basis of a set of attributes (Figure 1) are interpreted as partial indicators of importance. In terms of conjoint analysis, the term "partial utility" is used. Then the value of the profile (card) is the sum of the corresponding partial importance, i.e. the sum of the partial utilities.

The relative importance of each attribute was found by using the relative fraction of ranges of partial utilities for each $\mathrm{i}$-th attribute:

$$
A_{i}=\frac{\max _{j} \hat{a}_{i j}-\min _{j} \hat{a}_{i j}}{\sum_{i}\left(\max _{j} \hat{a}_{i j}-\min _{j} \hat{a}_{i j}\right)}
$$

where $\hat{a}_{i j}$ - coefficients of the empirical regression equation.

In the calculation of partial utilities, the programming language $\mathrm{R}$ was used for further statistical processing.

One of the advantages of a conjoint method is the ability to analyze data obtained from the experts (partial utilities, general utilities, etc.) at the personal level. However, for managerial purposes, the data obtained at the individual level must be transferred to the group level. For the part-worth model, aggregation can be obtained in several ways. As noted in the work of Wittink D., Krishnalnurthi L. (1981), the conclusions depend on the sequence of such procedures, and the procedure itself is selected depending on the purpose of the study. For the purposes of this study, the aggregation procedure (in this case, averaging) was performed at the utility level.

Ratio (1) for each scenario determines the ranking of "y", which made it possible to organize the scenarios in terms of the probability of their implementation.

The relative impact on the results of the innovation project is obtained by the formula (2).

Having considered all the possible scenarios for each financial result $(100 \%, 80 \%, 60 \%, 40 \%, 20 \%, 0 \%)$ and determined the probability of each probable cash flow from the planned one, the probability of a specific financial result of the project realization was determined (Table 2).

(T3) Based on the identified risk factors, the level of their impact on the implementation of innovative projects was estimated. For this purpose, an analytical model of the financial results objective target (objective) function of the innovative project implementation was formed, taking into account market risks.

In the paper of Solntsev (Solntsev S. et al., 2013), the target function was determined through net discounted cash flow (NCF) as follows:

$$
\left\{\begin{array}{c}
N C F=N C F^{+}-N C F^{-} \\
N C F^{+}=\sum_{\mathrm{i}} \frac{C F_{i}^{+}}{(1+r)^{i}}, N C F^{-}=\sum_{\mathrm{i}} \frac{C F_{i}^{-}}{(1+r)^{i}},
\end{array}\right.
$$

where $\mathrm{NCF}$ - net cash flow for the period; $\mathrm{NCF}^{+}$ incoming net cash flow; $\mathrm{NCF}^{-}$- outgoing net cash flow; $\mathrm{CF}_{i}^{+}$- incoming cash flow in the i-th period; $\mathrm{CF}_{i}^{-}$- outgoing cash flow in the i-th period; $r$ discount rate.

In the present study, the value of net present value (NPV) was adjusted as a target function and adjusted for losses that may result from the realization of market risks.

The range of the random variable distribution, which is defined as the percentage of NCF net cash flow input, is given in Table 2 .

\section{Table 2}

\section{NCF Net Cash Flow Input Distribution Range}

\begin{tabular}{|l|c|c|c|c|c|c|}
\hline $\begin{array}{l}\% \text { of NCF } \\
\text { implementation }\end{array}$ & $100 \%$ & $80 \%$ & $60 \%$ & $40 \%$ & $20 \%$ & $0 \%$ \\
\hline $\begin{array}{l}\text { Subjective } \\
\text { probabilities }\end{array}$ & $\mathrm{p}_{100}$ & $\mathrm{p}_{80}$ & $\mathrm{p}_{60}$ & $\mathrm{p}_{40}$ & $\mathrm{p}_{20}$ & $\mathrm{p}_{0}$ \\
\hline
\end{tabular}

Source: Own elaboration

The mathematical expectation of the Net Cash Flow $(N C F)$ input value is suggested to be written as follows:

$$
\begin{aligned}
& N C F_{\text {exp }}=\boldsymbol{E} N C F=\left(p_{100}+0,8 p_{80}+0,6 p_{60}+\right. \\
& \left.+0,4 p_{40}+0,2 p_{20}\right) \cdot N C F
\end{aligned}
$$

where $E$ is the mathematical expectation sign. 
Table 4

Planned release of innovative products (estimated by experts of the ITC "Bezstykovyi Shliakh")

\begin{tabular}{|l|c|}
\hline \multicolumn{1}{|c|}{ The innovative product name } & Number of units \\
\hline Track rail-welding self-propelled machine & 24 \\
\hline Track self-propelled ballast cleaning machine & 12 \\
\hline Ballast leveling machine & 12 \\
\hline Dynamic track stabilization machine & 24 \\
\hline Catenary installation and maintenance machine & 32 \\
\hline Track renewal system & 12 \\
\hline
\end{tabular}

Table 5

Estimated total cost of the innovation project, thousand UAH (estimated by experts of the ITC "Bezstykovyi Shliakh")

\begin{tabular}{|l|c|}
\hline \multicolumn{1}{|c|}{ Components of the project cost } & Cost, thousand UAH. \\
\hline Conducting scientific research & 1645.2 \\
\hline Research and development work & 3290.4 \\
\hline Preparation of pilot production and release of pilot and pilot batches of innovative products & 6580.8 \\
\hline Creation of industrial production & 332043.2 \\
\hline Project total cost & 343559.6 \\
\hline
\end{tabular}

It is suggested to take the mathematical expectation of NPV as a target function of NPVexp:

$$
N P V_{\text {exp }}=\mathrm{E} N P V=N C F_{\text {exp }}-I C O \text {, }
$$

where ICO is the initial cash outflow.

It should be noted that the expected $\mathrm{NPV}_{\text {exp }}$ with market risk adjustment is always less than the NPV.

It is proposed to use the Internal Rate of Return (IRR) method in view of market risk adjustment $\left(I R R_{\exp }\right)$ to decide on the feasibility of investing in a project.

Further, the eligibility criterion commonly used for the IRR method was used in the work (Van Horne J., Wachowicz J., 2008). It means that the comparatively expected Internal Rate of Return (IRR $\exp$ ) with a hurdle rate (HR) that is eligible for adoption of an innovative project. Namely, if:

$$
I R R_{\text {exp }} \geq H R
$$

then the project is accepted and otherwise it is rejected.

\begin{tabular}{|lr|}
\hline \multicolumn{2}{|c|}{ Conjoint regression results: } \\
coefficient \\
(Intercept) & 6.686 \\
Input_cash_flow|80\% & 3.006 \\
Input_cash_flow|60\% & 2.007 \\
Input_cash_flow|40\% & 1.357 \\
Input_cash_flow|20\% & 2.176 \\
Input_cash_flow|0\% & 2.163 \\
R1|TRUE & -0.661 \\
R2|TRUE & -0.032 \\
R3|TRUE & -0.328 \\
R4|TRUE & 0.578 \\
R5|TRUE & -0.071 \\
\hline
\end{tabular}

Figure 2. Categorical regression coefficients (R-code)

Source: Own data

\section{Results and discussion}

The approbation of the presented methodology for assessing market risks of innovative projects was carried out on the example of a planned innovation-technology cluster (ITC) "Bezstykovyi Shliakh". The possible participants may be: "Ukrainian Railways" SEO, Institute of Electric Welding named after. E.O. Paton (Kyiv), "Kakhovka Electric Welding Equipment Plant" PJSC (Kherson region, Kakhovka), “Track repair technologies" LLC NPP (Lviv), "Dnepropetrovsk turnkey plant" SEO (Dnipropetrovsk), "Diprotrans" SRDITC LLC (Kharkiv), State Economic and

\begin{tabular}{|c|c|c|c|}
\hline \multicolumn{4}{|c|}{ Conjoint part-worths: } \\
\hline \multicolumn{3}{|c|}{ Attributes Levels } & PW \\
\hline Input & low & $100 \%$ & 0.000 \\
\hline Input & low & $80 \%$ & 3.006 \\
\hline Input & low & $60 \%$ & 2.007 \\
\hline Input & low & $40 \%$ & 1.357 \\
\hline Input & low & $20 \%$ & 2.176 \\
\hline Input & low & $0 \%$ & 2.163 \\
\hline $\mathrm{R} 1$ & FALSE & 0.000 & \\
\hline R1 & TRUE & -0.661 & \\
\hline $\mathrm{R} 2$ & FALSE & 0.000 & \\
\hline $\mathrm{R} 2$ & TRUE & -0.032 & \\
\hline R3 & FALSE & 0.000 & \\
\hline R3 & TRUE & -0.328 & \\
\hline R4 & FALSE & 0.000 & \\
\hline $\mathrm{R} 4$ & TRUE & 0.578 & \\
\hline R5 & FALSE & 0.000 & \\
\hline R5 & TRUE & -0.071 & \\
\hline Base & & 6.686 & \\
\hline
\end{tabular}
Technical University of Transport (Kyiv). Within

Figure 3. Estimates of partial utilities (R-code) Source: Own data 
the framework of ITC, the implementation of such an innovative project as "Creation and organization of track equipment production for mechanization of construction and operation of the upper structure of the track with welded rails, including the highway" is planned. The developer of the project is the Technopark "Institute of Electric Welding named after. E.O. Paton". The project is aimed at the production of modern hightech innovative products of mechanical engineering for the repair and maintenance of railway tracks. This project is very important for the solution of the problem of reliable high-speed transportation of export cargoes in the direction of ports and the western border.

The planned term of implementation of the innovation project covers five years, according to which the planned production of the products presented in Table 4.

The estimated total cost of the project is given in Table 5 .

(T1) The risks that have the greatest impact on the innovation project were then identified. The most
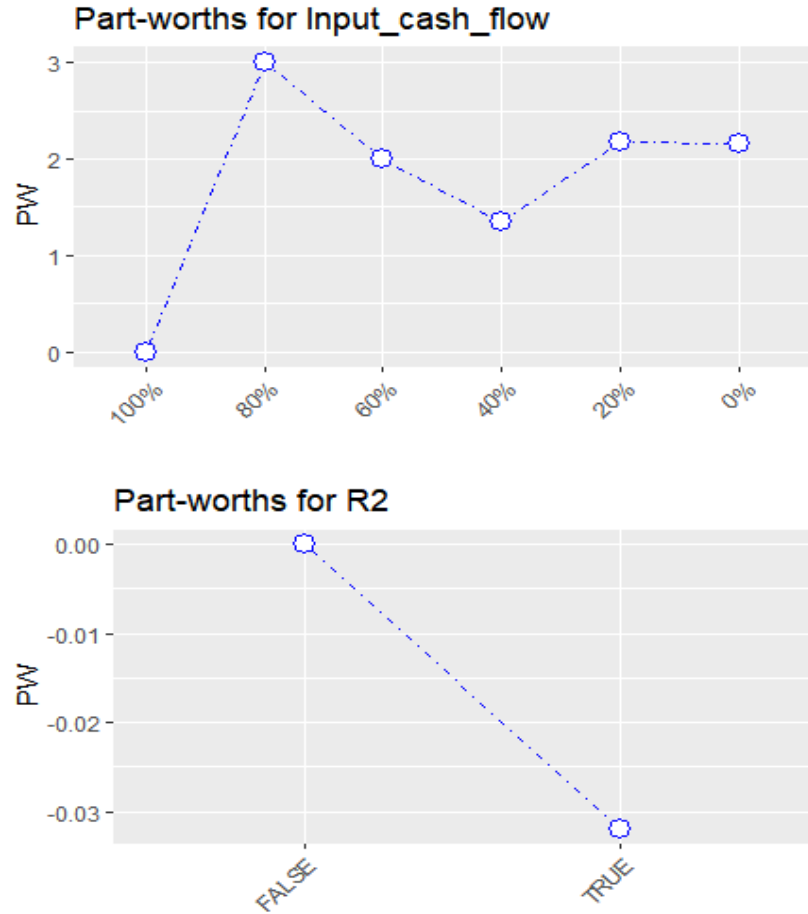

Part-worths for R4

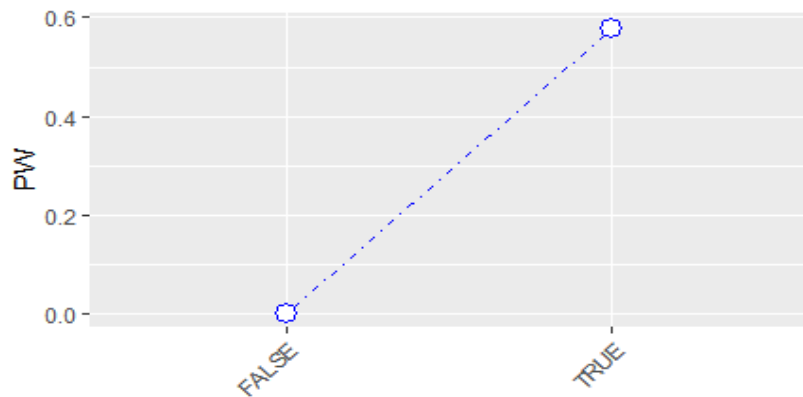

influential risk factors for innovations were market risks and inter-corporate relations risks.

The authors found that the risks of innovative machine-building QIS projects are all the underappreciated value of introducing new engineering products / technologies. That means, that the major risks of machine-building QISs are related to the launch of innovative (or technologically updated) competitive mechanical engineering products and the specific risks of inter-corporate relations within QIS.

As noted, based on quality marketing research, specific market risks of bringing innovative products of mechanical engineering to the market are:

- market rejection of new technologies (R1);

- negative reaction of the market to the discrepancy between the declared and actual characteristics of innovative products (R2);

- "copying" products by the other competitors (R3);
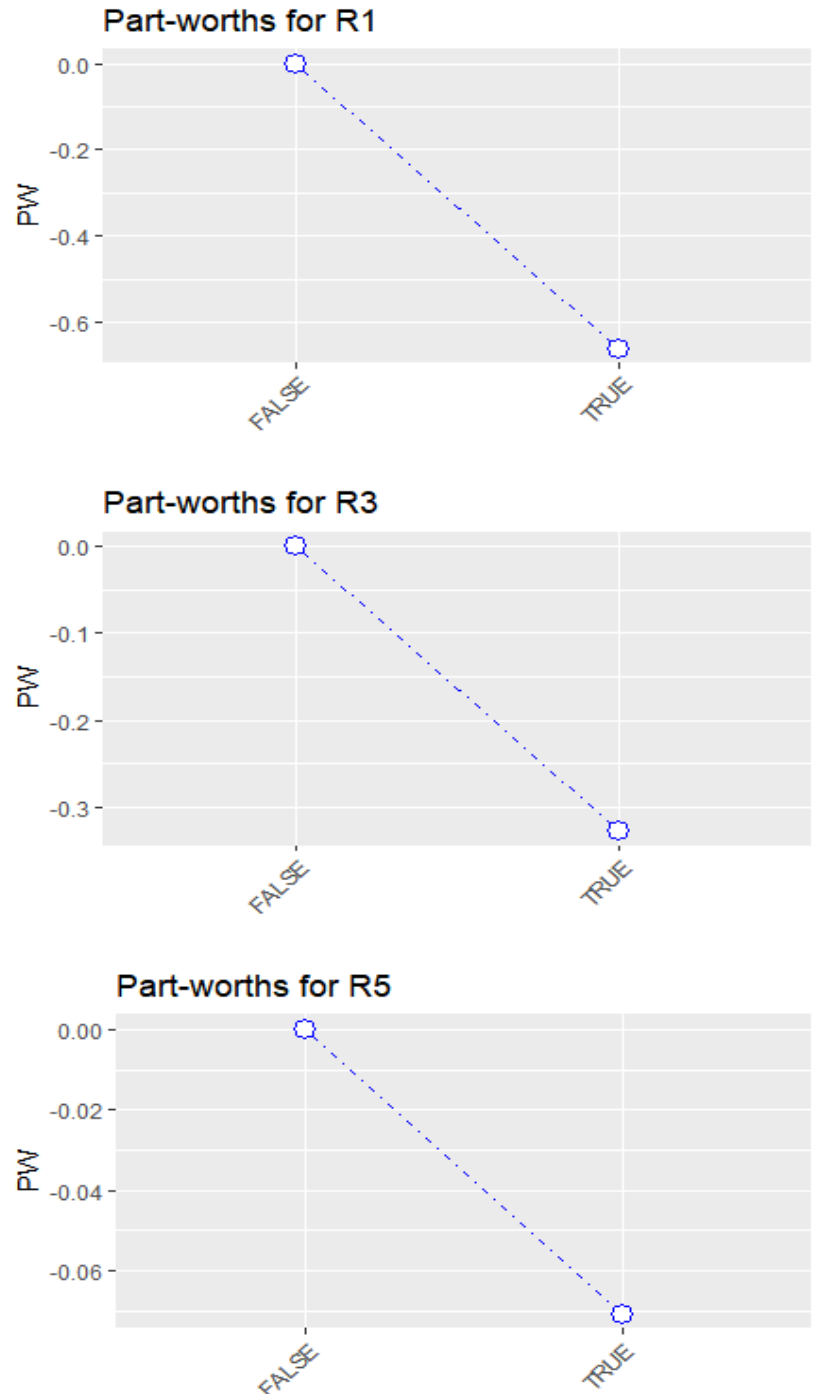

Figure 4. Structure of attributes of an innovative project within the ITC "Bezstykovyi Shliakh" (R-visualization) 
- loss of mutual trust of QIS participants in the process of implementation of the innovative project (R4);

- low-quality information of marketing research (R5).

(T2) Using the programming language $\mathrm{R}$, the coefficients $\hat{a}_{0}, \hat{a}_{i j}$ of the categorical regression equation (1), which are shown in Figure 2, were calculated.

As it is accepted in the conjoint analysis, common utilities are found using the partial utility coverage formula (2) and are presented in Figure 3.

The results are shown in Figure 4.

Considering the structure of risk attributes (Figure 4), we can conclude that only for risk R4 (loss of mutual trust of QIS participants in the process of implementation of the innovation project) experts perceive the probability of implementation of this risk event more than its failure.

According to Figure 4, taking into account the share of each risk utility $\mathrm{R} 1-\mathrm{R} 5$, the value of the relative impact of the risks on the financial result of the innovation project within the ITC Bezstykovyi Shliakh" was obtained (Figure 5).

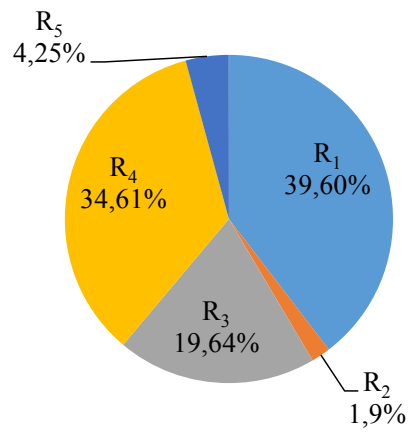

Figure 5. The relative impact of risks on the financial result of an innovation project within the framework of ITC "Bezstykovyi Shliakh"

Source: Own elaboration
From Figure 5, it can be concluded that for the innovation-technological project within the framework of ITC "Bezstykovyi Shliakh", the most influential are the risk of market rejection of new technologies (R1) and the risk of loss of mutual trust of QIS participants in the process of implementation of the innovation project (R4).

Taking into account formula (2), an indicator $\mathrm{y}$ is defined for each scenario, which allowed to rank the scenarios according to the criterion of their probability of realization (Figure 6).

From Figure 6, it is obvious that the first scenario is the most likely scenario, where we have the $80 \%$ share of the planned input cash flow, even if there is a risk of "loss of mutual trust among QIS participants in the process of implementing the innovation project" (R4). The second most likely scenario is: $80 \%$ of the planned input cash flow in the face of risks of "negative market reaction to the discrepancy between declared and actual characteristics of innovative products" (R2) and "risk of loss of mutual trust of QIS participants in the process of implementing the innovation project" (R4). The following scenarios are similarly treated.

After considering all the possible scenarios for each partial utility " $100 \%$ of the planned input flow", " $80 \%$ of the planned input flow", etc., the probability of loss of income due to market risks is determined (Table 5).

(T3) All of these market risks may have an effect on the failure to meet the projected revenue, which means to reduce incoming cash flows in the project implementation process.

The NPV, NPV ${ }_{\text {exp }}$, IRR and $I_{R R}$ exp values of the project were calculated using formula (3) and Table 6 values using Microsoft Excel. At a discount rate of $30 \%$ the value of NPV was 641669,8 thousand UAH and $\mathrm{NPV}_{\text {exp }}$ was 133606.7 thousand UAH, while IRR was $94 \%$ and IRRexp $-45.67 \%$. The desired profitability level, ie the

\begin{tabular}{|c|c|c|c|c|c|c|c|}
\hline \multicolumn{8}{|c|}{ predict (conjoint_allrespondents, profiles.all) \%> arrange (desc (Prediction)) } \\
\hline & Input_cash_flow & $\mathrm{R} 1$ & R2 & R3 & $\mathrm{R} 4$ & R5 & Prediction \\
\hline 1 & $80 \%$ & FALSE & FALSE & FALSE & TRUE & FALSE & 10.269730 \\
\hline 2 & $80 \%$ & FALSE & TRUE & FALSE & TRUE & FALSE & 10.237263 \\
\hline 3 & $80 \%$ & FALSE & FALSE & FALSE & TRUE & TRUE & 10.198302 \\
\hline 4 & $80 \%$ & FALSE & TRUE & FALSE & TRUE & TRUE & 10.165834 \\
\hline 5 & $80 \%$ & FALSE & FALSE & TRUE & TRUE & FALSE & 9.941891 \\
\hline 6 & $\ldots \ldots \ldots \ldots \ldots \ldots \ldots \ldots$ & ............ & ……... & ............ & …..... & ............ & .............. \\
\hline
\end{tabular}

Figure 6. Ranks of the "incoming cash flows - set of risks that occur" scenarios within the Innovation project within the framework of ITC “Bezstykovyi Shliakh” (R-code snippet)

Source: Own data

Table 5

Distribution range of NCF + net cash flow input

\begin{tabular}{|l|c|c|c|c|c|c|}
\hline$\%$ of NCF+ implementation & $100 \%$ & $80 \%$ & $60 \%$ & $40 \%$ & $20 \%$ & $0 \%$ \\
\hline Subjective probabilities & 0.1304 & 0.1914 & 0.1711 & 0.1579 & 0.1749 & 0.1743 \\
\hline
\end{tabular}

Source: Own elaboration 


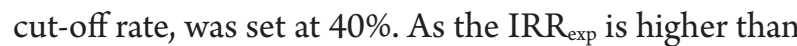
the cut-off rate, according to the eligibility criterion (4), the innovative project "Creation and organization of track equipment production for mechanization of construction and operation of the upper structure of the track with welded rails, including the highway" within the framework of ITC "Bezstykovyi Shliakh" is an attractive investment.

\section{Conclusion}

The study developed and tested a methodology for assessing the impact of risks on innovative projects within the machine-building QIS, based on the use of a conjoint methodology.

The conjoint approach is psychometric in origin and is an empirical method of exploring the benefits of multidimensional choice situations. Today, conjoint analysis has proven to be an effective method of collecting and analyzing data in various fields of research and business. The conjoint concept is based on the decomposition of the order scale of judgments (rankings) into the metric scale of the constituents (attributes) of the object under study. The lack of sufficient database of accumulated data does not allow to use classical methods of statistics for analysis in case of innovative projects. Therefore, conjoint, which does not appeal to regression analysis of data, is a topical methodology in the study of innovative projects within quasi-integration structures.

Qualitative research has made it possible to identify market risks for innovative projects. The following more influential market risks have been identified: the risk of market rejection of new technologies; the risk of a negative market reaction to the discrepancy between the declared and actual characteristics of innovative products; risk of "copying" products by the other competitors; risk of loss of mutual trust of QIS participants in the process of implementation of the innovation project; the risk of low-quality information of marketing research.
The peculiarity of the present study is the use of conjoint to analyze the relationship between project risks and financial results. Selection of the most likely scenarios is based on a trade-off between the economic efficiency of the innovation project and the combination of market risk events. The probability of different scenarios of generating project revenue was evaluated using a conditional methodology with the use of a computer simulation of an experiment partial factorial design. The most likely scenarios were found to be scenarios with a financial result of $80 \%$ of the planned input cash flow. Among the risks that have the greatest impact on the financial result of the studied innovation project are the risks of market rejection of new technologies (39.6\%) and the risk of loss of mutual trust by QIS participants in the process of implementation of the innovation project (36.61\%).

The study identifies the probabilities of different levels of cash inflows. Probability of $13.04 \%, 19.14 \%$, $17.11 \%, 15.79 \%, 17.49 \%, 17.43 \%$ estimated income generation at the levels of $100 \%, 60 \%, 80 \%, 40 \%, 20 \%$, $0 \%$ of the planned revenues. Based on the data obtained, the mathematically expected internal rate of return on investment was calculated. We have determined that the investment expected internal rate of return is greater than the cut-off rate. Therefore, it was concluded that it is advisable to invest the project.

Thus, an attempt was made to create a basis for a risk management system in innovative projects based on an assessment of their impact on project performance using a conjoint methodology. It was proven that conjoint procedures were very effective in management decisionmaking. The proposed method of assessing the impact of risks on the financial results of innovative projects within the machine-building QISs can be used in more general situations, which need further investigation.

\section{Acknowledgments}

This research received no specific grant from any funding agency in the public, commercial, or not-forprofit sectors.

\section{References:}

Behrens, W., \& Hawranek, P. (1991). Manual for the Preparation of Industrial Feasibility Studies. Vienna: United Nations Industrial Development Organization.

Bragina, T. E., \& Tabunshik, G. V. (2011). Fuzzy analysis of project risk. Information processing systems, 3(93), 15-20.

Chen, J. M. (2014) Measuring Market Risk Under the Basel Accords: VaR, Stressed VaR, and Expected Shortfall. International Journal of Finance, 8, 184-201. doi: 10.2139/ssrn.2252463

Cherenkov, A. (1999). Application of the method of conjoint analysis marketing study. Marketing in Russia and abroad, 4, 24-28.

Committee of Sponsoring Organizations of the Treadway Commission (2007). Gerenciamento de riscos corporativos: estrutura integrada. $2^{\text {nd }}$ ed. United States: COSO.

Dreshchinsky, V.A., \& Markov, M.A. (2010). Risk assessment methodology in promotion of innovations projects. Innovations, 2(136), 100-104.

Etges, A., Souza, J., \& Neto, F. (2017). Risk management for companies focused on innovation processes. Production, 27, e20162209, doi: 10.1590/0103-6513.220916 
Ferdous, R., Khan, F., Sadiq, R., Amyotte, P., \& Veitch, B. Fault and Event Tree Analyses for Process Systems Risk Analysis: Uncertainty Handling Formulations. Risk Analysis, 31(1), 86-107. doi: 10.1111/j.1539-6924. 2010.01475.x

Green, P., Krieger, A., \& Wind, Y. (2001). Thirty Years of Conjoint Analysis: Reflections and Prospects. Marketing Engineering, 31(3), 56-73. doi: 10.1287/inte.31.3s.56.9676

Green, P., \& Rao, V. (1971). Conjoint Measurement for Quantifying Judgmenteal Data. Journal of Marketing Research, 8, 355-363. doi: 10.2307/3149575

Green, P., \& Srinivasan, V. (1990). Conjoint analysis in marketing: new developments with implications for research and practice. Journal of marketing, 54(4), 3-19. doi: 10.2307/1251756

Hanke, J., \& Wichern, D. (2009). Business forecasting. $9^{\text {th }}$ ed. Pearson Education, Prentice-Hall.

Hauser, J., \& Rao V. (2004). Conjoint analysis, related modeling, and applications. Marketing Research and Modeling: Progress and Prospects, 14, 141-168. doi: 10.1007/978-0-387-28692-1

Havenaar, M., \& Hiscocks, P. (2012) Strategic alliances and market risk. Drug Discovery Today, 17, pp. 824-827. doi: $10.1016 /$ j.drudis.2012.03.008

Hsu, C.-C., \& Sandford, B. A. (2007). The Delphi Technique: making sense of consensus. Practical Assesment, Research \& Evaluation, 12(10), 1-7. doi: 10.7275/pdz9-th90

Illiashenko, S. (2010). Strategic management of enterprise innovative activity on basis of marketing of innovations. Actual problems of economics, 12, 111-119.

International Organization for Standardization (2009). ISO 31000:2009: risk management: principles and guidelines 2009. Geneva: ISO.

Kaplan, R., \& Mikes, A. (2016). Risk Management - The Revealing Hand. Applied Corporate Finance, 28(1), 8-18. doi: $10.1111 /$ jacf.12155

Kovalev, P.P. (2017). Features of risk assessment of investment projects. Economics: yesterday, today and tomorrow, 7 (5A), 251-260.

Krantz, H., Luce, R., Suppes, P., \& Tversky, A. (1971). Foundations of Measurement. New York, NY: Academic Press. Laburtseva, O. (2012). Management of innovations marketing risks. Marketing and Management of Innovations, 4, 15-22.

Luce, R.D., \& Tukey, J.W. (1964). Simultaneous Conjoint Measurement: A New Type of Fundamental Measurement. Journal of Mathematical Psychology, 1, 1-27. doi: 10.1016/0022-2496(64)90015-X

Malhotra N., \& Birks D. (2007). Marketing Research: an applied approach: 3rd European Edition. Harlow, UK: Pearson Education.

McConnell, P. (2016). Strategic Risk Management. London: Risk Books.

Merton, R., \& Kendall, P. (1946). The focused interview. American Journal of Sociology, 51, 541-557. doi: $10.1086 / 219886$

Miorando, R., Ribeiro, J., \& Cortimiglia, M. (2014). An economic-probabilistic model for risk analysis in technological innovation projects. Technovation, 34, 485-498. doi: 10.1016/j.technovation.2014.01.002

Miura, R., \& Shingo, O. (2000). Statistical Methodologies for the Market Risk Measurement. Asia-Pacific Financial Markets, 7, pp. 305-319. doi: 10.1023/a:1010077117199

Morgan, J. P. (1996). RiskMetrics: Technical Document. Retrieved January 12, 2020 from: http://www.jpmorgan.com/ RiskManagement/RiskMetrics/RiskMetrics.html

Rutkauskas, A., \& GinevičiusI, A. (2011). Integrated management of marketing risk and efficiency. Journal of Business Economics and Management, 12(1), 5-23. doi: 10.3846/16111699.2011.555357

Slepukhina, J., \& Kharchenko, G. (2007). Features of modern risk assessment methods of investment projects. Journal of new economy, 1(18), 104-116.

Solntsev, S., \& Ovchynnikova, A. (2011). Assessment of the marketing risks of bringing a new product to the market. Marketing education in Ukraine. 356-365.

Solntsev, S., \& Ovchynnikova, A. (2013). Model of Assessment of Marketing Risks in Investment Projects. Business Inform, 12, 105-110.

Solntsev, S., \& Zhygalkevych, Zh. (2019). Creation and development of quasi-integration structures on the basis of machinebuilding enterprises. Business navigator, 3(52), 128-132.

Solntsev, S., \& Zhygalkevych, Zh. (2020). Determining the attractiveness of innovative projects within quasistructures based on a conjoint approach. Marketing and Digital Technologies, 4(1), 15-28.

Steiner, M., \& Meißner, M. (2018). A User's Guide to the Galaxy of Conjoint Analysis and Compositional Preference Measurement. Marketing ZFP - Journal of Research and Management, 40(2), 3-25. doi: 10.15358/03441369-2018-2-3

The CBC System for Choice-Based Conjoint Analysis Copyright Sawtooth Software, Inc. Orem, Utah USA. Retrieved February 24, 2020 from: https://www.sawtoothsoftware.com/download/techpap/cbctech.pdf Thuesen, K. (2007). Analysis of Ranked Preference Data. Retrieved February 5, 2020 from: http:// citeseerx.ist.psu.edu/ viewdoc/download?doi=10.1.1.89.152\&rep=rep1\&type=pdf 
Vol. 6, No. 3, 2020

Van Horne, J., \& Wachowicz, J. (2008). Fundamentals of financial management. $13^{\text {th }}$ ed. Pearson Education, Prentice-Hall.

Vargas-Hernández, J. G., Noruzi, M. R., \& Sariolghalam, N. (2010). Risk or innovation, which one is far more preferable in innovation projects? International Journal of Marketing Studies, 2(1), 233-244. doi: 10.5539/ijms. v2n 1 p 233

Wang, Q. (2009). Multi-agent Assessment on Marketing Risk Based on Evidence Theory. International Conference on Electronic Commerce and Business Intelligence. doi: 10.1109/ECBI.2009.33

Wittink, D., \& Krishnalnurthi, L. (1981). Aggregation issues in conjoint analysis. Working Paper, No. 580. Retrieved February 5, 2020 from: https://www.gsb.stanford.edu/faculty-research/working-papers/aggregationissues-conjoint-analysis

Xing Y., \& Guan Q. (2017). Risk management of PPP project in the preparation stage based on Fault Tree Analysis. IOP Conference Series Earth and Environmental Science, 59. 1-9. doi: 10.1088/1755-1315/59/1/012050 